Res Publica. Revista de Historia de las Ideas Políticas ISSN: $1576-4184$

http://dx.doi.org/10.5209/RPUB.56473

\title{
La Tertulia política del Ateneo de Madrid de Agustín García Calvo
}

\author{
Jesús Ruiz Fernández*
}

Recibido: 17de marzo de 2016 / Aceptado: 10 de mayo de 2017

Resumen. Para Agustín García Calvo la Tertulia política del Ateneo de Madrid era un caso insólito en el mundo. De igual forma podría decirse que es insólito que un autor de su talla intelectual y vastísima obra no disponga prácticamente de ningún estudio académico. En las líneas que siguen sostengo que, aparte de ser la mejor manera de acercarse a su pensamiento, la tertulia fue el núcleo de su vida y obra. Esa alternativa que tantas veces se le pedía, y que él prefirió ofrecer, en lugar de con palabras, con hechos, en acto. El artículo también se refiere a la relación de la tertulia del Ateneo con la Asamblea libre de la Puerta del Sol del 15M y las asambleas de 1965.

Palabras clave: razón; contradicción; poder; revuelta estudiantil del $65 ; 15 \mathrm{M}$.

\section{[en] Agustín García Calvo's Political Discussion Group in the Ateneo of Madrid}

Abstract. Agustín García Calvo thought that Ateneo's Political Discussion Group was an unusually unique case in the world. In the same way, it could be said that it is unusually unique the inexistence of academic research about an author of his intellectual stature and with so vast works. In this article, I state that, besides being the best way of getting closer to his thinking, the Ateneo's Political Discussion Group was the nucleus of his life and works. It was also the alternative that he was asked so many times. He preferred offering, instead with words, with facts, in act. Finally, this article also mentions the relationship between the Ateneo's Political Discussion Group and the 15M Movement's Free Assembly in the Puerta del Sol and the assemblies of 1965.

Keywords: reason; contradiction; power; 1965's student's riot; 15M Movement.

Sumario: 1.La única cosa que funciona bien. 2. La lucha contra el poder que está allí arriba. 3. La tertulia interminable.

Cómo citar: Ruiz Fernández, J. (2017). La Tertulia política del Ateneo de Madrid de Agustín García Calvo, en Res publica 20.2, 325-339.

Es unánimemente reconocida la influencia que de una manera u otra Agustín García Calvo ha ejercido sobre la intelectualidad española. Sin embargo, el estudio de su obra es menos que mínimo. La razón fundamental estriba, claro está, en la indiferencia mutua que la academia y él se regalaron. Pero como no todo es academia en este mundo, habrá que buscar alguna otra razón complementaria. Y yo creo hallarla,

\footnotetext{
Universidad Nacional de Educación a Distancia (UNED)

jruizfer@madrid.uned.es
} 
más que en el escollo de enfrentarse a una producción tan vasta, variada y dificultosa como la suya, en el peligro que se corre de tergiversarla, o, peor aún, domesticarla. Por lo menos es lo que más me retrae de escribir este artículo. En sus 37 adioses al mundo advirtió del riesgo de quedar registrado en el archivo fúnebre e inocuo de la Historia: "eternamente falsificado, si me dejo, si te dejan los amigos que lo hagas"1. $\mathrm{Si}$ al final me he decidido, ha sido animado por el hecho de que él escribiera sobre otros autores: Heráclito, Sócrates, Unamuno..., así como sobre sí mismo. En Cosas que hace uno podemos encontrar un resumen de los descubrimientos de la Tertulia política del Ateneo de Madrid $^{2}$, tema del que me voy a ocupar, y, pensándolo bien, también García Calvo no estaba exento del peligro de falsificarse a sí mismo.

Como digo, me voy a centrar solo en una parte de su obra: la tertulia. Concretamente en la Tertulia política del Ateneo de Madrid, la última de las grandes tertulias en que ha sido tan pródiga esta ciudad, así como la última de las tertulias en que tan pródiga fue la vida de Agustín. Y lo voy a hacer, en primer lugar, convencido de que la tertulia fue el centro de su vida y su obra. Me parece acertada la expresión de Javier Echeverría: "Agustín García Calvo destaca por lo que escribió, pero ante todo por lo que hizo"3, y creo que lo que hizo ante todo fue la tertulia. Tertulia, que fue la fuente y desembocadura de su pensamiento, y la respuesta a esa pregunta qué tanto se le hacía: ¿Y tú qué alternativa das? Así, sin palabras, con hechos; sin ideas, en acto. $\mathrm{Y}$ en segundo lugar, porque creo que es la mejor manera de acercarse a una obra que generalmente se califica de muy difícil. Es la ventaja que tiene la enseñanza oral sobre la escrita: la posibilidad de solicitar al autor que aclare su pensamiento ${ }^{4}$.

\section{La única cosa que funciona bien}

La Tertulia política del Ateneo de Madrid se desarrolló con Agustín García Calvo desde 1997 hasta su muerte en 2012, todos los miércoles de 8,30 a 10 de la noche, en la Sala de la Cacharrería. Las tertulias que el zamorano tuvo durante toda su vida las llegó a ver como "preparación" (2006-8-23)5 de esta. Entre otras, pueden citarse la que Antonio Tovar tenía en el desaparecido café Castilla de Salamanca, a la que García Calvo acudía siendo estudiante de Clásicas. Y posteriormente, ya dirigidas por él, las de Zamora y Sevilla, en los años 50 y 60; la famosa tertulia La Horda del café La Boule d'Or del Barrio latino de París, y las que, una vez vuelto a España del exilio, tuvo en los cafés Arranz y Manuela, y en la Fundación La Aurora Intermiten-

A. García Calvo, 37 adioses al mundo, Zamora, Lucina, 2000, p. 117.

A. García Calvo, Cosas que hace uno, Zamora, Lucina, 2010, pp. 49-57.

J. Echeverría, “iMuera la muerte!”, en J. Lázaro (ed.), Encuentros con ¿Agustín García Calvo? Unos y otras, Madrid, Triacastela, 2013, pp. 111-114, aquí p. 111.

4 Con todas las matizaciones que se quiera, pero sería interesante incardinar a García Calvo en una tradición. No hay que olvidar que, según José Gaos, tanto la filosofía española como el pensamiento hispanoamericano, tienen preferencia por la palabra oral frente a la escrita (Obras completas, vol. VI, México, UNAM, 1990, pp. 58-87). Citaré indicando entre paréntesis la fecha de la tertulia: año, mes, día. En la web de la Editorial Lucina, http:// www.editoriallucina.es/seccion/tertulias-del-ateneo.html [Consulta: 20-12-2016], se hallan las transcripciones y las grabaciones. De 2006 hasta noviembre de 20012 están todas; el resto de los años faltan bastantes. En total hay recogidas más de cuatrocientas tertulias, gracias al trabajo sobre todo de Teresa Rodríguez Vázquez y Javier Hebrero. Las transcripciones también se encuentran en Baúl de Trompetillas, de Javier Sanmartín, http:// bauldetrompetillas.es/agustin-garcia-calvo/tertulias/en-el-ateneo/ [Consulta: 20-12-2016]. 
te. García Calvo inició la tertulia del Ateneo “el año '97, en que, liberado ya de todo cargo de enseñanza oficial, he venido a montar en el Ateneo eso que no se sabe bien qué es, pero querría ser lo contrario de la enseñanza"6.

Que la tertulia fue el centro de su vida se refleja en su impresionante fidelidad a la del Ateneo. En los 15 años solo faltó unas pocas veces, y por enfermedad ${ }^{7}$. Había tertulia incluso en julio y agosto, los días de fiesta, en Navidad... Si no, sería porque estaba cerrado el Ateneo. El último año de su vida, la enfermedad no le dejó muchas veces acudir, pero la reunión se realizaba dirigida por sus discípulos. En 2009 se asombraba de su duración: "semana tras semana, a la misma hora, una cantidad de gente que no baja mucho, ni siquiera en vacaciones, de las ciento, $[\ldots]$ es $[\ldots]$ tan raro que casi uno podría asegurar que no ha sucedido nunca en el mundo" (2009-1230). Y aun así la disfrutó tres años más. Y todavía perdura en 2016, mantenida por sus discípulos ${ }^{8}$.

La importancia de la tertulia se advierte también en expresiones suyas como que era "casi el rato que más cerca se puede decir que vivo" (2010-6-9), o que los tertulianos eran la gente que más quería en el mundo (2011-8-10). Es fácil entenderlas cuando se adentra uno en su pensamiento. Como cuando dijo que era la única cosa que conocía que funcionara bien (2006-9-13). Durante sus últimos meses de enfermedad estuvo muy pendiente de ella, y sabemos por Isabel Escudero que aun en momentos tan críticos seguía siendo lo que más le importaba (2012-5-23). Como también confirma su hijo Víctor: "las cosas que más le han ayudado a sentirse vivo" en sus últimos tiempos "fueron sus intervenciones con el 15-M y mantener la tertulia de los miércoles en el Ateneo de Madrid".

La asistencia a la tertulia, hemos visto, era de unos cien de media. Bien es verdad que algún verano se dio la circunstancia de llegar a ser muy pocos. Entonces peligraba la tertulia, porque los miembros se sentían como en familia. Y es que ni en soledad, ni en familia, ni con los amigos, ni en el trabajo, se puede hacer lo que se hacía allí, esto es, razonar, o, como él prefería: dejarse hablar. Se deja uno hablar cuando desaparece, es decir, cuando deja de opinar, de emitir opiniones individuales, que no son a la postre más que las ideas establecidas, lo que ya está dicho por estar mandado. La democracia, este régimen desarrollado en que hemos venido a parar como si fuera el final de los tiempos, se sustenta en la idea de que cada cual tiene su opinión, cuando todo el mundo sabe que las opiniones se construyen desde arriba. Agustín pensaba que era en la tertulia donde más podía descargarse del nombre propio, donde lo que dijera estaba más cerca de sonar a común. Por eso, pudiera resultar desorien-

6 A. García Calvo, Cosas que hace uno, op. cit., p. 38. Isabel Escudero, poeta y escritora, y compañera de vida, tanto privada como pública, de Agustín García Calvo durante casi treinta y seis años, fue quien gestionó el traslado de la tertulia desde el pequeño y abarrotado piso de La Aurora Intermitente al Ateneo, lo que supuso su institucionalización. Entonces ella dirigía la sección de Literatura y Pensamiento de la histórica sociedad de la calle del Prado, siendo su presidente Carlos París.

$7 \quad$ Sin contar el último año, de las tertulias grabadas se extrae que faltó dos miércoles.

8 Actualmente la dirigen Isabel Escudero y José Luis Caramés, “que, aparte de matemático, me acompaña desde hace casi medio siglo" (Ibidem, p. 52), aunque, como es natural, con menor asistencia de público. Este hecho de que todavía perdure, lógicamente me ha planteado otra duda: la de si escribir el artículo en pasado o en presente. Al final me he decidido a hacerlo mayormente en pasado, pero ha de tenerse en cuenta que la tertulia se sigue desarrollando fielmente a cómo era — de 2013 hay algunas recogidas en la web de la Editorial Lucina.

9 A. Corbillón, "La rebeldía de Agustín García Calvo se apaga a los 86 años", en Elnortedecastilla.es, Valladolid, 1-11-12, http://www.elnortedecastilla.es/20121101/mas-actualidad/cultura/rebelda-agustn-garca-calvo-201211012129.html [Consulta: 20-12-2016]. 
tador la utilización del término tertulia en esta denominación de Tertulia política - como también ocurre con el término política - acostumbrados como estamos a las tertulias al uso, tan extendidas hoy día en los medios de comunicación, donde se discuten opiniones a trompicones. "Esta se llama tertulia, seguramente se llamó así por modestia, pero desde luego no tiene que ver nada con esa especie de entrecruce de opiniones" (2009-9-9). Normalmente se habla con el fin de imponer ideas: a los demás o a uno mismo; pero cuando desaparece esta finalidad las palabras encuentran solas su orden. Arte que lo único que requiere es práctica, hasta automatizarlo. Así, nuestro zamorano recuerda cómo de joven se preparaba las clases o los discursos escribiéndolos, aprendiéndolos de memoria-, hasta que acabó por despreocuparse y dejarse hablar (2008-11-26). Por eso, le molestaba mucho que se pensara que quien hablaba era Agustín García Calvo. Porque lo contrario de la opinión es la verdad, la evidencia u obviedad, la perogrullada: común, de sentido común: "Yo aspiro a decir lo que cualquiera siente" (2012-1-11), aquello sobre lo que cualquiera pudiera decir: "Sí, eso es lo que yo había pensao, había querido decir, y no lo había visto claro cómo hacerlo" (2011-6-8).

La dificultad de sacudirse la personalidad individual en lugares como los referidos anteriormente se debe a que son conjuntos cerrados donde cada participante ocupa una posición bien definida. La tertulia, en cambio, era lo suficiente vaga y vaporosa como para no saber quiénes la componían ni cuántos eran. Estos entran, esos salen, aquellos están desde el principio, estos otros se fueron y han vuelto, etc. Su heterogeneidad resultaba ser su mayor virtud (2011-6-8): señores y señoras trajeados, acomodados en los enormes sillones de la Cacharrería, mezclados con jóvenes de aspecto hippie sentados por el suelo; sin que faltaran tampoco ni el vagabundo (2011-6-8) ni el loco (2011-11-30). García Calvo presumía de tener "alguna habilidad de aguja para enhebrar cosas de las más dispares" (2011-11-30) ${ }^{10}$.

El carácter indefinido de la tertulia era lo que la convertía en el centro de la vida y obra de García Calvo. En este sentido, solo las asambleas del año 65 y el $15 \mathrm{M}$ de 2011 podían equiparársele. Muchas veces se refirió a cómo aquellas constituyeron un punto de inflexión que dividió en dos su vida y su obra: "Cualquier cosa que me oigáis decir, cualquier cosa de las que estoy haciendo ahora, viene de lo que aprendí entre los estudiantes en rebeldía en aquellos años, desde el 65 y poco más" (2011-5-4) ${ }^{11}$. Por eso pudo comenzar su primera intervención en la Puerta del Sol el 15M diciendo: "Yo estaba esperando esto desde hace cuarenta y tantos años, cuarentayséis" $"$.

10 Mary Sol de Mora Charles también se refiere a lo variopinta que era la tertulia de La Boule D’Or (“Agustín García Calvo. En memoria”, en Encuentros con ¿Agustín García Calvo? Unos y otras, op. cit., pp. 99-102, aquí p. 100). Sin embargo, la tertulia del Ateneo no contó con la asistencia asidua de algunos personajes habituales en las anteriores, como Rafael Sánchez Ferlosio, Fernando Savater, Félix de Azúa, Víctor Gómez Pin y Antonio Campillo, entre otros.

11 En un panfleto de 1968 o 1969 destinado a analizar la situación de la Universidad, concibe la posibilidad de conversión de las asambleas de estudiantes en algo parecido a las tertulias: "un proceso [...] sumamente deseable, que es la paulatina u ocasional transformación de las asambleas o tribunas, frecuentemente consagradas a motivos político-anecdóticos, en debates verdaderos sobre temas que incluso pudieran parecer especulativos o teóricos, dado que nada más hermoso apenas puede imaginarse que esa violenta inserción de la especulación en el fervor político, de la que bien parece que no podrán sino salir ganando tanto la una como el otro" (A. García Calvo, "Panfleto destinado a un análisis de las organizaciones docentes con el propósito de contribuir a que el curso 1968-... se quede definitivamente abierto", en Actualidades, Zamora, Lucina, 1980, p. 207).

12 “Agustín García Calvo en Sol”, 19 de mayo de 2011, Editorial Lucina, http://www.editoriallucina.es/entra- 
De la misma manera que le molestaba su nombre propio, no solía ser bienvenido ningún otro, y advertía que era un error acudir a la tertulia a ver si lo que se oía ya lo había dicho Zaratustra, Confucio o Antonio Machado. Toda esa información, que nos llega a través de la educación y los medios, es "el arma principal del Poder para impedir el pensamiento y el sentimiento, y hasta diría la vida" (2012-2-29). Veremos más adelante cómo la mayor parte de la filosofía, literatura, ciencia, cultura en general, ha estado al servicio del poder. Pero como no dejaba de ser solo la mayor parte, siempre cabía la posibilidad de que sin esperarlo saltara la liebre y pudiera asomar algo aprovechable. Así desfilarán por la tertulia Heráclito y Parménides, los dos prefilósofos compañeros de viaje más sobresalientes de Agustín García Calvo; también Sócrates, y en menor medida Jesús de Nazaret, Freud, Dom Sem Tob, Antonio Machado, etc. Como puede verse, la tertulia era lo contrario del proceder actual de la filosofía, reducida a mera doxografía, historia de las opiniones de los filósofos.

Las tertulias tenían siempre la misma estructura. Comenzaban con un sermón de Agustín, y a continuación intervenía el público. El ruego era dejarse hablar, si bien también se admitían opiniones personales aunque solo fuera para demolerlas. Insistía sobre todo en la expresión de dudas sobre su sermón, dudas que eran "el aliento de la tertulia" (2006-10-4). Él mismo presentaba muchos de sus descubrimientos con severas dudas. A veces hacía preguntas a los tertulianos para ver si le iban siguiendo. O pedía ayuda al público para resolver problemas que, decía, le atormentaban. En lugar de los de siempre, prefería que intervinieran los nuevos, a los que animaba a superar su miedo a hablar porque "para que las cosas vayan bien basta con quitarse uno de en medio" (2011-7-27).

Condición de la tertulia era utilizar el lenguaje corriente y moliente, el román paladino en el que el pueblo suele hablar con su vecino. Más adelante veremos cómo todo lenguaje es mentira justo en lo que respecta a su parte semántica, la de los significados - mundo del que se habla—; pero por lo menos con el lenguaje vulgar nos vamos arreglando, vamos tirando para comunicarnos. Porque otra cosa son los lenguajes técnicos — científico, filosófico, religioso-, hechos para engañar a base de una jerga tramposa e ininteligible, pretendidamente significativa. En la telaraña de su terminología se balancean, por ejemplo, las escuelas filosóficas, presumiendo de

da/19-de-mayo-de-2011_109.html [Consulta: 20-12-2016]. También está en libro: La alegría de lo inesperado. Prólogo de Isabel Escudero, Árbol de Poe, Málaga, 2011. El pronunciamiento estudiantil de febrero y marzo del 65 no fue un episodio de la lucha contra el Régimen, sino "el primer brote, al menos en Europa, de las revueltas universitarias semejantes que luego florecieron por doquiera” (A. García Calvo, Cartas de negocios de José Requejo, Zamora, Lucina, 1981, p. 87). Agustín García Calvo pensaba que justo Mayo del 68 fue el canto de cisne de estas revueltas, a pesar del "truco repetido y por tanto odioso" (2011-5-25) de los historiadores de centrarse tanto en este hecho. De igual modo, la Acampada de la Puerta del Sol del 15M fue pionera de las que al poco florecieron por el mundo, como Occupy Wall Street. Por eso, el fenómeno no era "nada español", sino "una cosa que se refiere simplemente al régimen que domina el mundo primero" (2011-5-25). Si las revueltas del 65 fueron producto de la aparición del Estado de Bienestar, las de 2011 lo serían de su envejecimiento, una vez que se vio lo que había dado de sí ("Agustín García Calvo en Sol”, 19 de mayo de 2011, op. cit.). Sobre la presencia de García Calvo en el 15M no me extenderé, pues ya tengo un artículo publicado: “Agustín García Calvo en el 15M", Las Torres de Lucca, 8, pp. 247-279. Solo comentar que en 2011 se le juntaron dos tertulias, una el miércoles y otra el jueves. Veinte reuniones — un corrillo de amigos y transeúntes_-, al lado del templete de la Puerta del Sol, desde el 19 de mayo hasta el 29 de septiembre. La estructura, la misma que la del Ateneo: sermón e intervenciones, si bien el contenido era algo más accesible. En la web de la Editorial Lucina están las veinte grabaciones y transcripciones: En Sol 2011, http://www.editoriallucina.es/seccion/en-sol-2011.html [Consulta: 20-12-2016]. En Baúl de Trompetillas, las transcripciones, http://bauldetrompetillas.es/agustin-garcia-calvo/tertulias/en-sol/ [Consulta: 20-12-2016]. 
haber logrado la cuadratura del círculo, precisado lo esencialmente vago. Claro está, todas contra todas. Una buena forma de servir al poder, al que le encantan los líos.

Es un tópico que a Agustín García Calvo no se le entiende. Valga como ilustración el chiste, que a este propósito contó un tertuliano, de las viejecitas que comentan al salir de la Iglesia: no se le ha entendido nada pero el cura ha estado estupendísimo (2008-7-9). En este punto yo creo que habría que distinguir entre claridad y dificultad. García Calvo siempre presumió de hablar muy claro: "Uno de los vicios que tengo es que suelo hablar demasiado claro, en contra de la confusión que es la regla en la comunicación y la información reinante" (2008-3-26). La dificultad de entenderle, que es obvia y de la que él era consciente, la explicaba por la costumbre, producto de nuestra mala educación, de asimilar cosas bastante tortuosas y complejas, mientras que las simples y perogrullescas se nos escapan. Además, tenemos los oídos demasiado duros, taponados de opiniones personales, y nos cuesta oír. Es decir, que el problema de no entender no es nuestra ignorancia, sino el excesivo saber. No oír, no entender, es nuestra táctica de defensa ante cualquier ataque al poder, porque nosotros, cada uno, también somos el poder.

Sin embargo, hay que señalar la dificultad añadida de que García Calvo no sea nada escolar. Ya en su librillo de iniciación al latín de 1956, Viriat-i Vit-a, advierte en el Prólogo su intención de no dárselo masticado a los niños: “¿Por qué presentarles frasecillas insignificantes, cuya largura y simplicidad no fatigue ni hiera sus tiernas mentes? No: que las hiera que las estire, hasta hacerlas capaces de comprender un poco mejor lo abstracto, lo largo y lo complejo" "13. Por eso indicaba yo más arriba la ventaja que tenía la tertulia sobre sus libros y otras publicaciones: "Aquí debería ser más fácil, porque al fin y al cabo, pues estáis oyendo directamente y por tanto hay menos escapatoria para no entender [...] los escritos permiten muchos más subterfugios, muchas más trampas, por eso son los medios que el Poder favorece" (2012-3-7).

Agustín, en su sermón inicial comenzaba planteando un tema u ocurrencia, aunque enlazándolo con los días anteriores, e intentaba que el público se atuviera a él, sin permitir en la medida de lo posible las distracciones, que interpretaba como huida. La tertulia seguía su hilo miércoles a miércoles, a través de los meses y de los años. Ahora bien, dadas sus características, tal hilo no podía ser rígido, planificado de antemano, impuesto desde arriba. La tertulia misma, el propio razonamiento iba haciendo camino al andar. Entrecruzándose a veces con alguna circunstancia personal, o temporal: los carnavales, Semana Santa, el Día de Difuntos. La temática, variada: cualquier cosa divina o humana, aunque siempre con un sello común ${ }^{14}$.

\section{La lucha contra el poder que está allí arriba}

Preguntado por la tertulia en una entrevista, Agustín García Calvo proporcionó un resumen muy oportuno y completo:

M. López López, “Agustín García Calvo, filólogo clásico”, en Minerva 26, 2013, pp. 301-315, aquí p. 303.

14 Recordando las asambleas madrileñas del 65, escribe Fernando Sánchez Pintado: "Era un año de asambleas, se encadenaban y siempre había una nueva razón para hacer otra al día siguiente. En realidad, eran siempre la misma razón y la misma asamblea" ("Agustín 1968”, en "Encuentros con ¿Agustín García Calvo? Unos y otras", op. cit., pp. 83-91, aquí p. 85). De igual forma, puede decirse: siempre la misma razón y la misma tertulia. 
Es una forma de desconocimiento, nos dedicamos a hacer contra la realidad lo que se puede, que se hace hablando, porque la realidad necesita fe; sin la fe el dinero no se sostiene, los créditos. A la fe se la puede atacar hablando y esa es la primera acción, hablar, que es hacer, contra la realidad. Se debate contra el Poder, contra la Realidad y se intenta, esa es la táctica, más que soltar ideas que uno tenga y contrastarlas con otras, simplemente dejarse hablar. Hay confianza en la lengua corriente, en la lengua vulgar, contra las jergas de la educación, de la ciencia, de la política, de los Medios. Es una suelta de ideas. Y si llevo tanto tiempo con esto es porque sé que no es la mayoría, pero siempre hay alguien dispuesto a hacer algo en contra de lo que le han impuesto ${ }^{15}$.

Sin embargo, aún es posible sintetizar más; incluso con tres palabras, como hizo Agustín en respuesta a un niño que, curiosamente, estaba presente un día, y que le preguntó que para qué servía la tertulia: "para luchar contra el poder que está allí arriba" (2009-7-5). Lucha, poder y arriba, he aquí las tres palabras clave. Porque el hecho de que el poder esté arriba, confiere a la lucha que es la Tertulia política un sentido que no es el habitual cuando nos ocupamos de política. De política están llenas las conversaciones privadas, los informativos de los medios... Es como si no se parara de hablar sobre el poder. Pero no del poder que está allí arriba, sino de sus títeres. Por eso la Tertulia política era un lugar diferente, inédito, en el que se podían oír expresiones de los tertulianos como: "Yo lo que me trae aquí es que es el único sitio donde se puede oír o decir algo distinto" (2010-6-9), o: "Me abres ventanas a otro mundo que eran desconocidas para mí" (2010-6-9). La política de la tertulia era "una política que es la política que no es la Política que hacen los políticos que hacen la política" (2010-1-20). Todos esos personajes ilustres, famosos, perfectamente intercambiables unos por otros, aparte de para el negocio de los medios, solo sirven de distracción del verdadero blanco de la lucha. Todos "hemos nacido en una cárcel" (2006-2-22), todos somos esclavos del poder; pero hay grados de esclavitud, y cuanto más alto se está en la pirámide social, más esclavo se es. La Tertulia Política fue, como él mismo dice, en lo que desembocó su dilatada actividad política: "hasta que hemos venido a dar con una vía de política, pacífica y tranquila, al menos aparentemente, en esa tertulia del Ateneo de Madrid"16.

La cuestión del poder podría constituir un problema ontológico en el pensamiento de Agustín García Calvo, si él no se hubiera burlado de la ontología, y si tal pensamiento no fuera más allá del $\operatorname{ser}^{17}$. Porque en nuestro inclasificable zamorano hay tres niveles del haber, el cual es más amplio que el ser. Hay ser; hay lo contrario del

15 L. Lara, "Agustín García Calvo. La educación transmite valores, los del dinero". Entrevista, en Cuadernos de Pedagogía 416, 2011, pp. 57-60, aquí p. 60. http://www.editoriallucina.es/recursos/apps/pdf/Agustin-Garcia-Calvo-CdP.pdf [Consulta: 20-12-2016].

16 A. García Calvo, Cosas que hace uno, op. cit., p. 48.

17 "Anarquismo ontológico" llama Antonio Campillo al "original sistema de pensamiento" de García Calvo ("En memoria de Agustín García Calvo", webs Universidad de Murcia, 2013, https://webs.um.es/campillo/miwiki/ doku.php?id=noviembre_2013 [Consulta: 20-12-2016]. En su conferencia autobiográfica, Cosas que hace uno, y repasando sus múltiples actividades: poética, teatral, filológica, política, etc., cuando llega a la última, a la que podría llamarse filosófica, porque trata de "lo que puede tal vez decirse más profundo" (op. cit., p. 49), prefiere llamar a la sección "Realidad/verdad" (Ibidem, pp. 49-57). En la última entrevista que se le hizo, contestó al entrevistador: "No olvides que si contra la Gramática estoy a medias, contra la Filosofía estoy del todo" (G. Arnáiz, "La última entrevista con Agustín García Calvo (2012)”, en Encuentros con ¿Agustín García Calvo? Unos y otras, op. cit., pp. 313-321, aquí p. 320). 
ser, que no es la nada, sino lo sin fin —no fin, límite, definición—, también llamado lo desconocido, y hay el resultado de la encarnación del ser en lo sin fin, que es la realidad de la que nosotros y todas las cosas existentes formamos parte. El poder que está allí arriba es este ser, ideas o ideales perfectos, que, sin embargo, se realizan imperfectamente, porque "perfecto no hay nada; sería sacarlo de la Realidad" (200810-29). En la tertulia se oirán frecuentemente expresiones como "la realidad no es todo lo que hay" o "las cosas no son lo que son", que sintetizan el pensamiento de Heráclito y Parménides. En este, la vía de la verdad es el ser, porque en la realidad no puede haberla, porque en ella anida la contradicción heraclítea: querer ser y no poder - en los mismos ríos entramos y no entramos, somos y no somos. Una vaca podrá ser una excelente vaca, pero nunca podrá ser la vaca; habrá de conformarse con una mera aproximación a la vaca verdadera, un más o menos o vagamente vaca. El descubrimiento más importante de la tertulia es el principio de contradicción de Heráclito, quien se nos ha transmitido falsificado como el filósofo del cambio, cuando en realidad es el de la contradicción. Precisamente las cosas cambian porque intentan realizar de nuevo el ideal de manera diferente a la fracasada, esto es, para seguir lo mismo. Ampliando el concepto de lenguaje, García Calvo sostiene que todas las cosas hablan a su manera -aunque nosotros no las entendamos-, eso sí, coincidiendo todas en el logos o razón común del defenderse constantemente y deshacerse, hundiéndose continuamente en lo sin fin.

Ahora bien, el hombre es un caso especial de cosa, un caso, diríase, patológico, al que el poder solivianta de manera extrema. Hay ideales de baja estofa - vaca, hombre-, y también otros más excelsos: Dios, uno, ser, todo, nada. En el resto de las cosas hay un equilibrio entre el ideal y no-ideal, debido a que a ellas solo acceden los ideales del más bajo estrato. Nosotros, en cambio, sufrimos el bombardeo de los superideales. Claro está que de manera ilusoria, porque por mucha fe que tengamos en creernos Dios, enteramente judíos o poseídos por el amor eterno, no somos más que cosas entre las cosas, tan torpes como ellas. Pero, en fin, esa es la vida del hombre, la de creer lo que no se ve, como decía el catecismo. Y así, contagiados de ese extremismo, humanismo, cometemos los excesos de que nos da noticia la Historia, las guerras y demás males de la humanidad. García Calvo se adhiere al intelectualismo socrático del nadie hace el mal a sabiendas, o el perdónales que no saben lo que hacen de Jesús de Nazaret. Los culpables son los ideales.

Detengámonos un momento en la afirmación anterior de creerse Dios. Es la cuestión del nombre propio, del uno, de ser enteramente nosotros. Obviamente, un ser así no puede morir. Sin embargo, curiosamente, tomamos conciencia de sí cuando aprendemos a través del lenguaje que tenemos que morir. Un psicoanálisis verdadero —no degenerado, como el freudiano-, en el sentido del me investigué a mí mismo heraclíteo o - del también falseado-conócete a ti mismo socrático, disuelve el tal uno como ideal del otro reino e imposible en este de la existencia.

La muerte es, además, imposible porque es siempre futura, y el futuro no existe. El futuro se abre ante nosotros como conciencia del fin, del ideal. Si los animales viven ahora, nosotros vivimos preocupados por el futuro, es decir, en el futuro, así como en un pasado mentiroso, construido con vistas al futuro. Ahora, que no es ni siquiera presente porque no dura, tiene un valor político, ya que elimina el fin, el poder.

Como ni en el futuro ni en el pasado puede pasar nada, como solo ahora pasa lo que pase, se crea un vacío en el que hacen su agosto el Capital y el Estado, los ad- 
ministradores de la muerte. Muerte en el sentido de no pasar nada, porque la otra, el deshacerse, el continuo morir es lo mismo que vivir. Capital y Estado cumplen dos funciones: proporcionar seguridad y sustitutos con que tapar el aburrimiento. Sustitutos, por supuesto, de más o menos, aproximaciones a lo bueno, que nunca llenan. Porque lo mismo que en la existencia no hay verdad, tampoco aquí puede haber algo de verdad bueno. Así, nos cambian la vida por la existencia.

La misión de la religión, filosofía, ciencia, será la de servir al poder, tapando las contradicciones, para que resplandezcan los grandes ideales, salvando la realidad para salvarme yo. Agustín García Calvo comentaba que desde siempre, desde niño, se había dado cuenta de que todo libro, ensayo, podía dividirse en dos partes: una crítica con los antecedentes, otra en la que el autor se vanagloriaba de haber solucionado los líos puestos de manifiesto en la parte anterior. Naturalmente, la primera era fructífera; la segunda, un timo. La divulgación, la educación, ocultan normalmente la confusión existente en la vanguardia de la ciencia. Como ocurre en la física cuántica, a la que la Tertulia política le concedió mucha atención a lo largo de los años. García Calvo presumía de haberse "estado, sobre todo entre Caramés y yo, tragando cerca de dos mil entradas en la Red y algunas otras contribuciones de científicos diversos" (2010-9-22). José Luis Caramés le ponía en las manos toda contribución sobre mecánica cuántica de científicos desmandados que hallaba en internet, donde relumbraba el desbarajuste reinante en las altas esferas de la física. Porque cuanto más honrado e inteligente se es, menos se entiende. Y, aunque todos aspiraban de una manera u otra a desliar los líos, por lo menos en lo que respecta a la primera parte, a la inteligente, toda esa información resultaba muy útil en una tertulia que procuraba perderse tanto como lo estaban todos esos físicos ${ }^{18}$. En Contra el Tiempo de 1993 y Contra la realidad de 2002 ya trató algo estas cuestiones físicas, "pero ha sido a partir de ahí, al paso de los debates y ocurrencias en la tertulia política del Ateneo madrileño $[\ldots]$ como he venido intentando entrar más a fondo en las teorías físicas, vigentes y contradictorias" ${ }^{19}$. Por cierto, en un determinado momento hubo quejas sobre tanta proliferación de física en la tertulia, contestando Agustín que la física era lo mismo que la política (2007-12-12).

Pero como cualquier otra cosa, estos productos culturales se hallan también sujetos a la ley de defenderse y deshacerse. La filosofía, por ejemplo: todas las filosofías definitivas que inundan los libros que las historian, y donde ninguna ocupa más de un capítulo, por más que en un determinado momento pudiera llegar a imponerse como filosofia perenne, oficial o de moda. Con su pretensión de explicar la realidad desde dentro de la realidad, no ofrecen sino un producto a la postre necesitado de explicación, un eslabón más del cuento de nunca acabar.

Resumiendo, el poder que está allí arriba es la realidad humana, la fe, la verdad, el uno, Dios, la muerte: "Es lo que nos toca, es a lo que hemos venido aquí, no se sabe de dónde ni por qué, pero vamos a seguir atacando a la Realidad" (2008-10-22). "Ésta es la acción política, la acción contra la Fe, en la que se pueden resumir cualesquiera cosas que aquí estemos haciendo" (2009-2-4). "La liberación es al mismo tiempo, como recordáis los que venís conmigo hace tiempo, liberación del Uno individual personal, y liberación del Hombre en su conjunto.

18 En ¿Qué es lo que pasa? (Zamora, Lucina, 2006, pp. 135-171) viene la lista de estas entradas en la Red de físicos desmandados.

19 Ibidem, p. 23. 
Somos aquí claramente antihumanistas" (2011-7-27). "Esta tertulia política contra lo que está es contra la Verdad" (2010-2-10). "En esta tertulia política estamos luchando contra Dios" (2010-11-10). "Es por lo que estamos aquí, en una tertulia como ésta, que es una tertulia contra la muerte" (2009-4-8). Por eso, era habitual que terminara las tertulias, por lo menos desde 2006, con "si el Señor nos deja nos vemos el próximo día".

La solución de Agustín García Calvo será la de hacernos cosas, la de renunciar al humanismo, tomando partido por la contradicción. Cambiar el proverbio latino de soy hombre y nada humano me es ajeno, por el de soy cosa y nada de las cosas me es ajeno. Vivir en la vaguedad. Como se vive en las asambleas, como de verdad se vive en la realidad — queramos o no verlo-, que "está resquebrajada, borrosa, indecisa, en contra de lo que ella misma pueda pretender" (2007-3-21). La propuesta sería ser menos: "ser buenos es ser menos" (2010-12-12).

El sujeto de la lucha contra el poder - la famosa y manida pregunta por el sujeto de la revolución-, en la circunstancia de la tertulia será lo sin fin, lo de abajo, lo que nos queda de vivo y que se resiste a someterse al poder de arriba. Lo que García Calvo llama pueblo - otra razón de que la tertulia se llame política. La pregunta de por qué se acudía a ella se planteó en una ocasión, y, desde luego, no se invocó ningún estímulo real, ninguna alabanza ni palmadita en el hombro de entendidos o autoridades. Las respuestas apelaron más bien a la razón y al sentimiento: amor a la verdad e insuficiencia de los sustitutos (2008-6-4). Si la esperanza es lo que nos hace mirar al futuro, la desesperación será lo que nos aleje de él y nos lleve a la tertulia. Quien no sintiera odio a la realidad, sobraba en ella. Agustín García Calvo acudía a veces con un estado de ánimo deplorable, asqueado especialmente del conformismo imperante. En determinada ocasión lamentó no contar con la paciencia de los grandes hombres: Buda, Jesús, Sócrates (2006-8-16).

Contra el humanismo, contra la fe de que la realidad es verdadera, de que se realicen los grandes ideales en ella, solo se puede luchar hablando, negando tal pretensión, desmintiendo la mentira. Negaciones, noes, que son las perogrulladas elementales e infantiles que uno emite cuando se deja hablar. Ahora bien, hablar es hacer. En la tertulia no se habla de política: se hace política. A la tertulia no se va a culturizarse: "Aquí no tenemos capacidad de conocimiento, somos unos desconocedores y lo poco que conocemos nos sobra" (2007-12-12). La misma respuesta que sufrió un tertuliano agradecido porque, según decía, estaba aprendiendo mucho: que a la tertulia se iba a desaprender (2010-6-9). Por otra parte, no es cierto que primero sea la teoría y luego la práctica, que se vaya de la teoría a la práctica. La distinción entre teoría y práctica es malintencionada. Si la parte semántica del lenguaje, su parte más superficial, nos constituye; la parte más profunda - mundo en el que se habla - nos desconstituye. Negar la constitución es un desconstituirse, y eso es un hacer. La razón, que en parte está fuera de la realidad, desconstituye su propia obra. En la tertulia, como en cualquier otro lugar, la función constitutiva estaba garantizada, y, todo lo más, se tenía confianza en que apareciera la otra, la destructiva.

Otra de las divisiones culturales malintencionadas es la de razón y sentimiento. Entender es sentir; las perogrulladas son "evidencias sensitivas" (2009-4-1). García Calvo rogaba no hacerse ideas de lo que se decía en la tertulia. "No vuestras opiniones: vuestro sentir" (2011-3-23), pedía a los tertulianos. Las ideas sobre la realidad no se entienden, porque la realidad no es verdadera. Todo lo más hay fe de que te has hecho una idea, pero en realidad no te la has hecho. Nadie ha entendido nunca nada, 
ni en religión ni en filosofía ni en ciencia. Pero no ha importado, pues para eso está la fe de que allí en lo alto alguien lo entiende: doctores tiene la Iglesia. Lo importante siempre ha sido hacernos creer que el mundo es inteligible, para así convencernos de que la sociedad es inteligible y concluir felizmente en nuestra propia inteligibilidad. Lo importante para la tertulia es en cambio sentir las contradicciones, la herida, el desasosiego. Cosa difícil, porque el saber mata el sentir. De modo que, machacando una vez tras otra, un día tras otro, un mes tras otro, se va creando un asco a lo que se venía haciendo de ordinario bajo el imperio de los grandes ideales.

Esta es la razón de que Agustín García Calvo nunca proponga alternativas, soluciones positivas. Cosa que se le ha criticado hasta la saciedad. Y es que no podemos concebir que se critique algo sin proponer nada a cambio. Incluso la mera negación pretende interpretarse como un sí, como cuando a Sócrates se le endosaba que no saber nada era ya saber algo. Agustín contesta a esto que decir no no es decir si al no. Decir no es una acción, un hecho; no es conocimiento. Lo primero que aprenden a decir los niños es no, incluso antes que mamá, y no saben lo que dicen. El mismo Aristóteles reconoce que Sócrates no tenía ninguna doctrina, que era solo una actitud. Agustín García Calvo era una especie de Sócrates redivivo, por plazas y ateneos criticando las ideas establecidas. Decir que las cosas reales son imperfectas, no es una afirmación, sino negar que sean perfectas. Decir que hay que hacerse cosa, no es una afirmación, sino negar que seamos dioses. Por eso la verdad es el descubrimiento, el hallazgo, el quitar el velo que recubre la realidad, alézeia (2012-10-17). Pero esa verdad, aparte de que no es un saber, sino una acción, no pertenece ya a la realidad.

Convendría detenerse un poco más en la cuestión de no, realizando unas cuantas matizaciones. En primer lugar, es importante distinguir entre no y el no, porque el no ya es una idea, una teoría, fácilmente asimilable por el sistema. La tertulia no es escéptica. En segundo lugar, cuando se reprochara a la tertulia su negatividad debería tenerse en cuenta que el poder se asienta sobre la prohibición, de modo que lo que se está haciendo es negar ese no. En tercer lugar, debería caerse en lo perogrullesco de que proponer una alternativa positiva a cualquier cosa sería proponer cambiar para seguir lo mismo. Las nuevas teorías científicas tienen mucho mérito en haber puesto de manifiesto los errores de las antiguas, pero no suponen un progreso en cuanto a la verdad, pues en un camino sin meta nadie va por delante. Suponen un progreso, en cambio, en complejidad e ininteligibilidad, y, además, cada vez más acelerado. Y, al igual que en la ciencia, en política, revolucionar — pacífica o violentamente- la realidad desde dentro de la realidad, esto es, utilizando las armas del poder, deriva inevitablemente en otro poder: también el cuento de nunca acabar.

¿Quiere esto decir que la tertulia prohíbe la filosofía, la ciencia o incluso la política derechona? No. La tertulia está solo contra la fe en la filosofía, la ciencia o la política derechona. Además, la tertulia no prohíbe nada. Ni siquiera recomienda. Las reglas solo sirven para crear la contradicción obediencia-repulsión y el ánimo de escapar de ellas a la mínima oportunidad. Las recetas son siempre futuras, y el futuro todo lo arruina: "Si tenemos algo que hacer mañana ése es el camino más seguro de que hoy no hagamos nada" (2008-10-22). Lo importante es no tener fe, y ya saldrá lo que tenga que salir. Sin buscarlo: de manera imprevista; cuando quiera, aprovechando las grietas de la realidad. Las asambleas del 65 no estaban previstas ni organizadas desde arriba, y, sin embargo, tenían su orden; se organizaban con el orden que hay en los animales, nubes o aguas del mar. Se tomaban decisiones, no por 
votación, sino con "gritos, abucheos, risas, llantos, todo lo que una gran asamblea puede producir" (2011-5-25).

El término inesperado es central en las asambleas del 65 , el $15 \mathrm{M}$ y la tertulia:

Desde entonces estoy viviendo de eso; es decir que cualesquiera de las cosas que haya hecho, más o menos políticas, hasta los últimos años de la tertulia del Ateneo viven de lo que aquello me enseñó o desengañó; que fue ante todo, lo inesperado, lo improbable ${ }^{20}$.

Sois la alegría, es la alegría de lo inesperado, de lo no previsto, ni por parte de las autoridades y gobiernos, ni por parte de los partidos de cualquier color, verdaderamente imprevisto: vosotros mismos o casi todos, hace unos pocos meses o semanas, tampoco lo preveíais que pudiera surgir. Aunque esto es así, la alegría es lo inesperado y no hay otra alegría ${ }^{21}$.

Tertulia del Ateneo de Madrid en la que llevamos los más de doce últimos años, con una asistencia de alrededor de ciento, miércoles tras miércoles sin vacaciones ningunas; que es por sí un fenómeno raro y hasta singular; y merece tal vez que lo tengan en cuenta, por aquello de lo inesperado que antes les decía ${ }^{22}$.

La lucha, por supuesto, es muy difícil; el poder de los ideales es aplastante, pesadísimo. Aunque hay algo que puede animarnos, pues el hecho de que el sistema se nos esté imponiendo constantemente a través de la educación y los medios revela al fin su fragilidad e inseguridad. Es posible arreglárselas en esta guerra que es el vivir cotidiano sin venderse demasiado, concluía Agustín García Calvo.

Quien solía llevar los descubrimientos de sus tertulias al papel. Así, algunos de los hallazgos del Ateneo aparecieron en ¿Qué es lo que pasa? de $2006^{23}$. Son descubrimientos en el sentido de desarrollos y precisiones de conquistas ya antiguas. Porque no creo que haya una evolución en el sentido de etapas o grandes cambios en el pensamiento de García Calvo ${ }^{24}$. Por otra parte, y como es lógico, muchas de las tertulias son reconocibles en los artículos periodísticos que iba escribiendo al tiempo, como los del diario La Razón, a los que se refería a veces los miércoles en el Ateneo. Sin que pueda decirse, sin embargo, que hubiera un paralelismo temático entre unas y otros.

A. García Calvo, Cosas que hace uno, op.cit., p. 46.

"Agustín García Calvo en Sol", op. cit., 19-5-2011.

A. García Calvo, Cosas que hace uno, op. cit., p. 48.

Antonio Campillo también se ha referido a esta relación tertulia-libro, recordando su participación en las tertulias de la cafetería Arranz durante dos años -otoño 1977 a verano 1979: "Durante el primer año, discutimos sobre el lenguaje [...] Más tarde, pude reconocer algunos de nuestros debates e incluso alguna de mis intervenciones en el diálogo Del lenguaje", de 1979. [...] Durante el segundo año, nos dedicamos a debatir sobre los fragmentos del libro de Heráclito, a partir de la traducción que Agustín nos ofrecía, y de esas sesiones nació la edición crítica de los fragmentos heraclitanos, titulada precisamente Razón común (Lecturas presocráticas II)" ("En memoria de A. G. Calvo", op. cit.).

24 Por ejemplo, con respecto a ciertos temas que trató en Lalia, en 1973, escribe en ¿Qué es lo que pasa? que ha "venido con los años a dar en este descubrimiento que hoy propongo" (op. cit., p. 11). 


\section{La tertulia interminable}

Quizás convendría plantearse la cuestión de la efectividad de la tertulia. No, por supuesto, con respecto a su éxito real —“aquí estamos contra el éxito ¿no?” (20121-18) - , sino más bien en el sentido de su eficacia negativa. Desde luego, en lo que respecta a su proyección exterior es evidente que cero. "Es una cosa muy fuera del Orden, y que no cuenta gran cosa" (2009-10-14):

Así que no podemos esperar, no puedo yo esperar que por ejemplo los ámbitos culturales o políticos del mundo dediquen a mis despotricaciones, en verso o en prosa o en tertulia, alguna atención y algún reconocimiento. Eso sería contra los intereses del Estado y del Capital de una manera tan clara que sería insensato pretenderlo. No puedo esperar un reconocimiento de prójimos ni mayorías (2009-9-16).

Peor aún, la tertulia llegó a plantearse si ella misma no sería a fin de cuentas un sustituto más y haber sido asimilada por el sistema (2009-10-7), concluyéndose con todas las dudas del mundo que se confiaba en que no (2010-10-20). Confianza, que es lo contrario de fe, resultado de la negación de que la realidad sea todo lo que hay.

Con respecto a su efectividad de puertas adentro, desde luego, ya era un gran mérito de la tertulia el hecho de que nadie se aburriera. "Yo muchas veces ya hace tiempo que me he permitido en cualquier sesión pública el decir que conmigo no se aburre nadie. Y además, es verdad, conmigo no se aburre nadie" (2012-1-11). La razón estaba en los temas de que se hablaba, vivos y comunes, y de la forma como se hablaba, de la alegría que se respiraba. Pues si la fe es aburrida — no hay nada más tedioso que un claustro o un consejo de administración-, su destrucción es de las pocas alegrías que puede haber en la vida. La alegría de la tertulia era como la de los niños o la risa del pueblo, tan diferente de esa risa sumisa que tanto abunda. Te llaman negativo, decía García Calvo, pero luego ves cómo la negación les da alegría $(2006-7-26)^{25}$.

Sin embargo, no todo salía tan bien. A duras penas conseguía que la gente se dejara hablar, $y$, lo que es peor, muchas veces sus intervenciones se interpretaban como opiniones, en lugar de como voz del común. Lo que le entristecía especialmente, ya que personalmente no se gustaba (2008-4-2) -incluso confesó en una ocasión que le asqueaba su hipocresía y pedantería (2008-4-2). Tan severo se mostraba con lo demás como consigo mismo; rara vez agradecía las intervenciones, y lo normal es que se mostrara bastante duro, incluso demasiado duro, como él mismo reconocía (2011-9-28). La razón es que se dejaba llevar por un sentimiento inmediato, automático, tanto en sus tirones de orejas como en su raro aplauso (2010-9-29). Le resultaba un tanto infantil y escolar preguntar para ver si la gente le iba siguiendo, pero con manifestaciones como la de más arriba no tenía más remedio. Ahora bien, el resultado muchas veces era decepcionante, sin que se salvaran ni los que le acompañaban habitualmente (2008-2-27). Otras veces tampoco encontraba en el público la ayuda

\footnotetext{
25 Lo cual contrasta con el juicio de Fernando Savater, al que las tertulias le acabaron aburriendo por previsibles: "Tanto las afirmaciones del maestro como las eventuales corroboraciones de los discípulos se convertían para mí en una especie de letanía" "“Contratiempo de recuerdos", en Encuentros con ¿Agustín García Calvo? Unos y otras, op. cit., pp. 53-67, aquí p. 65). Por cierto, a Savater se le podría aplicar el cuento de más arriba de lo mucho que vale la crítica frente a lo poco que aporta la contribución positiva.
} 
que necesitaba, y era frecuente oírle lamentarse de que siempre hablaran los mismos. En este sentido, el papel de Isabel Escudero fue, yo diría, importante en la tertulia, porque sus frecuentes intervenciones, y hasta confrontaciones con Agustín, servían para remover una atmósfera en la que flotaba un público a veces excesivamente entregado ${ }^{26}$. Además, a través de Isabel alcanzaban a la tertulia muchos de los reproches que se le hacían fuera ${ }^{27}$.

Otra dificultad era la tentación de sobrepasar la raya del no. Así, a veces tenía que advertir: "Si me he pasao diciendo algo positivo ha sido por descuido" (20113-9). "Porque claro, si lo que yo os he soltado es una Ontología, ¡válganos Dios!, entonces no hemos hecho nada" (2010-5-12). Si por razones pedagógicas se hablaba demasiado de lo que no se debía hablar, o se sacaban a colación ideas o imágenes - la misma imagen de arriba y abajo, para referirse al poder y al pueblo_-, era para borrar todo eso inmediatamente. No obstante, más de una vez se le recriminó haber pisado la línea roja.

Las pretensiones de la tertulia debían ser en todo caso modestas, sabiendo lo que cuesta desnudarse de ideas. García Calvo era consciente de que la mayor parte de los tertulianos asistían con el propósito de consumir cultura, que luego olvidarían rápidamente (1997-12-17). Pero incluso los más animosos no debían esperar grandes trances ni conversiones. Ni sacudidas vitales ni sentirse más desgraciado de lo normal: simplemente se decía no, y ya era mucho (2007-9-26). Su misma prolongación en el tiempo, a primera vista exitosa, era un arma de doble filo, porque mostraba lo difícil que es desempolvarse de fe. "Yo mismo no puedo presumir de estar desprendido de todo eso" (2011-9-28), admitía. Como eran interminables las mentiras, debía ser interminable la tertulia. Aunque tampoco había prisa. No hay prisa donde no hay futuro: "Si veis que alguien anda con prisa, si os veis cada uno de vosotros asimismo andar con prisa, ya podéis deducir sin más que aquello por lo que se mueve no valía la pena" (2011-9-14).

En resumen, la tertulia era lo suficientemente vaga y borrosa como para merecer desde los presupuestos de García Calvo el calificativo de "funcionar bien". Unas veces era una maravilla, otras lo contrario; unos días se centraba, otros se perdía; la mayor parte ni una cosa ni otra. A Agustín se le entendía aproximadamente —en diverso grado en función de la asistencia a la tertulia-; nunca del todo. Es cierto que dependía excesivamente de él, de su personalidad; pero más o menos se podía hacer algo que no fuera recibir doctrina. La prueba está en que todavía perdura. Es decir, que la tertulia funcionaba como todo en la vida, pues no dejaba de ser una cosa real. Ahora bien, la diferencia con respecto a cualquier otra empresa humana $-\mathrm{y}$ de ahí viene el juicio de funcionar bien-, radicaba en la ausencia de fe $-\mathrm{o}$, mejor, en la menor cantidad de fe. Esa es la desemejanza entre un Consejo de la ONU, donde se cree que se va a salvar el mundo, y la tertulia. En el primero también puede pasar alguna cosa de vez en cuando —y seguro que pasa_-, pero indudablemente las posi-

\footnotetext{
26 “Cómo podría yo mostrar mi amor leal a un insumiso más que siéndole desobediente?” (Isabel Escudero, “Tus propias artes y razones”, en Encuentros con ¿Agustín García Calvo? Unos y otras, op. cit., p. 228).

27 La cosa, al parecer, ya venía de antes: "Mis intentos de asistir a las tertulias que se convocaban en un pequeño bar de Malasaña fracasaron: el ambiente despreocupado, fresco y espontáneo de La boule D’Or ya no existía. Ahora, Agustín había sido elevado a la categoría de pope laico y los asistentes se comportaban como devotos cofrades. Lógico y perfectamente comprensible. Pero a los que habíamos tenido la fortuna de frecuentar a un Agustín cercano, humano y accesible..." (Alfredo Melgar "El camino de un zamorano con corazón”, Ibidem, pp. 93-97, aquí p. 97).
} 
bilidades son menores, dado lo definida que está dicha institución y del empeño que se pone en que no pase.

Lamentablemente, como todo es, al fin y al cabo, cosa de más o menos, pienso -y sirvan estas palabras como balance crítico- que en la tertulia las cosas podrían haber ido aún mejor. Desgraciadamente, las voces disonantes, como la de Isabel Escudero, brillaban por su ausencia, y los ataques de sinceridad de García Calvo no pasaban de mero ornamento. Las desavenencias siempre se interpretaban como distracciones y defensas, y este término de siempre delata que algo no funcionaba —ni funciona, puesto que la tertulia vive de su legado— - bien, por más que la ONU funcione peor. Mejor dicho, mucho peor. 